\title{
新建人工深水湖泊沉积物上覆水和孔隙水中溶解性有机质的光谱 特征
}

\author{
张 倩, 董 靖, 吉芳英**, 牛凤霞, 赵 艮, 沈秋实, 何 强 \\ (重庆大学三峡库区生态环境教育部重点实验室, 低碳绿色建筑国际联合研究中心, 重庆 400045)
}

\begin{abstract}
摘 要: 为了揭示湖库内源性污染物的分布、来源、组成及垂向分布特征, 以新建人工深水湖泊龙景湖为研究对象,采用 紫外一可见光谱和三维荧光光谱技术, 研究了该湖泊以成湖前用途划分的 3 个特征区域( 原河道底部、新淹没区底部和新 淹没区边坡) 的沉积物上覆水和孔隙水中的溶解性有机质 (DOM) 的光谱特征. 结果表明, 孔隙水中的 DOM 芳香性和腐殖 化程度高于上覆水; 孔隙水中疏水组分含量大于上覆水, 且水体中可能存在内源孔隙水释放的低分子量 DOM. 龙景湖上 覆水和孔隙水中的 DOM 主要源于水体自身的微生物, 自生源特征明显, 且可能存在新近释放到水体的有机质. 龙景湖沉 积物上覆水和孔隙水中的 DOM 以类腐殖酸和类蛋白质为主, 且随着深度增加, 类腐殖酸峰强度增强, 与龙景湖的建湖背 景有明显联系.
\end{abstract}

关键词 : 人工湖;沉积物;腐殖化;紫外一可见光谱;三维荧光光谱;内源污染;龙景湖

\section{Spectral characteristics of dissolved organic matter in overlying water and pore water of newly-built artificial lake sediments}

ZHANG Qian, DONG Jing, JI Fangying ** , NIU Fengxia, ZHAO Gen, SHEN Qiushi \& HE Qiang

(National Centre for International Research of Low-carbon and Green Buildings, Key Laboratory of Three Gorges Reservoir Region's Eco-Environment, Ministry of Education, Chongqing University, Chongqing 400045, P.R.China)

\begin{abstract}
In order to reveal the sources, compositions, distributions and vertical distribution characteristics of endogenous pollutants in lake sediments, the ultraviolet-visible spectroscopy and three-dimensional fluorescence spectrum technology were applied to study the spectral characteristics. Data used in this work including sediment samples collected from the original riverbed, the newly submerged bottom and the newly submerged edge along the lakeside from the newly-built artificial deep-water lake, Lake Longjing. The divisive criterion of sampling sites is the main applications of those lands before impoundment. Results show that the aromaticity and humification of dissolved organic matter (DOM) in pore water is higher than those of overlying water. The proportion of hydrophobic components in pore water is greater than that in overlying water, which means there might be internal input of low molecular weight DOM. Data indicates that DOM of each sample mainly come from aquatic microbial activity within the water body and newlyreleased organic matter might exist. DOM of overlying water and pore water in Lake Longjing sediments mainly include humic-like parts and protein-like parts with humic-like peaks detected in the deeper layers, which indicates a significant association with the construction background of Lake Longjing.
\end{abstract}

Keywords: Artificial lake; sediment; humification; ultraviolet-visible spectroscopy; three-dimensional fluorescence spectrum; internal source pollution; Lake Longjing

在湖泊生态系统中, 溶解性有机质 (dissolved organic matter, DOM) 是由腐殖质 (包括腐殖酸、富里酸和 腐黑物）、氨基酸、脂类、氨基糖、蛋白质和糖类等复杂有机物组成的不均匀混合物 ${ }^{[1]}$, 其初始物质主要来自 于水体动、植物的分泌物及其残体的微生物降解以及陆源有机物的输人 ${ }^{[2-3]}$. DOM 作为一种较为活跃的化

* 国家水体污染控制与治理科技重大专项(2012ZX07307-001) 和重庆市研究生科研创新项目 (CYB15041) 联合资助. 2016-12-10 收稿; 2017-06-01 收修改稿. 张倩(1993 ), 女, 硕士; E-mail: zhangqiancqu@ 126.com.

** 通信作者; E-mail: jfy@ cqu.edu.cn. 
学组分,在湖泊生态系统中扮演着重要角色,主要体现在对水体的酸碱性、营养物质有效性、重金属及有机 污染物等污染物质的环境行为等的重要影响 ${ }^{[4-5]}$. 湖泊沉积物是大量聚集和释放天然有机物和人为污染物 的载体 ${ }^{[6]}$, 湖泊中的沉积物/水界面是物质迁移转化最为活跃的地方, 通过表征湖库典型区域沉积物界面上 覆水和孔隙水中的 DOM 的光谱特征, 可以揭示湖库 DOM 的分布、来源、组成以及源汇特征, 对湖库内源性 污染以及湖泊富营养化的防控具有积极意义.

成湖初期的山地城市景观深水湖泊具有深水位、成湖前土地用途较复杂等特点, 成湖导致水动力变化, 水深增加, 水的流速减缓, 湖库多为封闭的静止或缓流水体 ${ }^{[6]}$. 成湖初期, 湖库具有较差的水体自净能力和 较小的环境容量, 加之生态环境的变化导致底泥有机质及营养盐的释放, 容易引发湖库的富营养化问题. 目 前, 国内外关于新建大型水库成湖初期的水质和营养物质迁移转化有一定报道 ${ }^{[6-7]}$. 同时, 国内外对于各种 水体及其沉积物中 DOM 的光谱特性有一些报道 ${ }^{[8-15]}$, 研究对象涉及河流 ${ }^{[8-10]}$ 、湖泊 ${ }^{[11,13]}$ 、海洋 ${ }^{[14]}$ 以及河 $\square^{[15]}$ 等. 王立英等 ${ }^{[13]}$ 运用紫外一可见吸收光谱和苂光光谱研究滇池北部沉积物孔隙水中 DOM 的含量组成 和剖面分布. 傅平青等 ${ }^{[1]}$ 利用菼光发射光谱和三维苂光光谱研究云贵高原湖泊红枫湖和百花湖中的 DOM 组成、苂光光谱特性和垂直分布情况. 然而在查阅资料范围内, 国内外对于水体中 DOM 的研究中很少涉及 人工深水湖泊成湖初期沉积物上覆水及孔隙水中 DOM 的光谱特性, 也鲜有关于人工湖泊成湖过程中污染 物 DOM 来源的探讨. 本文旨在探究新建人工湖泊沉积物上覆水及孔隙水中 DOM 的分布、来源、组成及垂向 分布特征, 进一步分析人工湖泊成湖前底泥特征对其的影响. 本文以 2011 年建坝蓄水形成的河道型深水湖 泊沉积物为研究对象, 按照蓄水前土地用途、沉积物形成时间及水深, 将湖泊沉积物划分为原河道底部沉积 物、新淹没底部沉积物以及新淹没边坡沉积物 ${ }^{[16]}$, 采用紫外一可见光谱和三维苂光光谱表征湖泊典型区域 沉积物孔隙水和上覆水中溶解性有机质 DOM 的特征, 阐释沉积物/水界面处上覆水与孔隙水中 DOM 光谱 特征的垂向变化, 分析其中 DOM 的分布、来源以及组成特征, 借以掌握湖泊水环境现状. 研究成果对湖泊水 质保持、污染控制和治理修复等后续工作具有理论指导意义, 为进一步揭示人工湖泊成湖过程中 DOM 的组 成、来源及其对湖泊富营养化的影响机制提供科学依据.

\section{1 材料与方法}

\section{1 研究区域概况}

研究区域位于重庆市园博园龙景湖 (图 1) 内. 龙景湖于 2011 年由大坝拦截蓄水形成, 水库水位最高处 达 20 30 m, 是典型的新建河道型深水水库. 龙景湖水 面总面积约 $0.67 \mathrm{~km}^{2}$, 大坝上游常水位标高 $306 \mathrm{~m}$, 死水 位 $296 \mathrm{~m}$, 总库容 663 万 $\mathrm{m}^{3}$, 调节库容 425 万 $\mathrm{m}^{3}$, 换水周 期约 2.5 年, 水源补给主要是降雨径流. 为研究龙景湖沉 积物上覆水和孔隙水中 DOM 的来源, 分析成湖过程中 污染物的来源及变化, 根据蓄水前土地用途、沉积物形 成时间及水深, 将沉积物划分为原河道底部沉积物、新 淹没区底部沉积物以及新淹没区边坡沉积物 ${ }^{[16]}$. 原河道 底部沉积物是龙景湖蓄水前就存在的河道, 龙景湖闸坝 拦截蓄水前未进行原河道清淤处理, 原本存在一定深度 的沉积物. 新淹没区底部沉积物是指蓄水前主要为植被 和农地的水位较深的中间沉积物, 新淹没区边坡沉积物 是指蓄水前为裸露土壤和碎石表层的水位较浅的边缘 区域沉积物, 建设初期施工拦截蓄水时未进行清库工 作, 存在有机质的蓄积. 龙景湖建设后基本切断了除面 源外的其他外源性污染源.

\section{2 样品采集与现场测定}

用沉积物柱状采样器 (Corer 60, Uwitec, Austria) 分

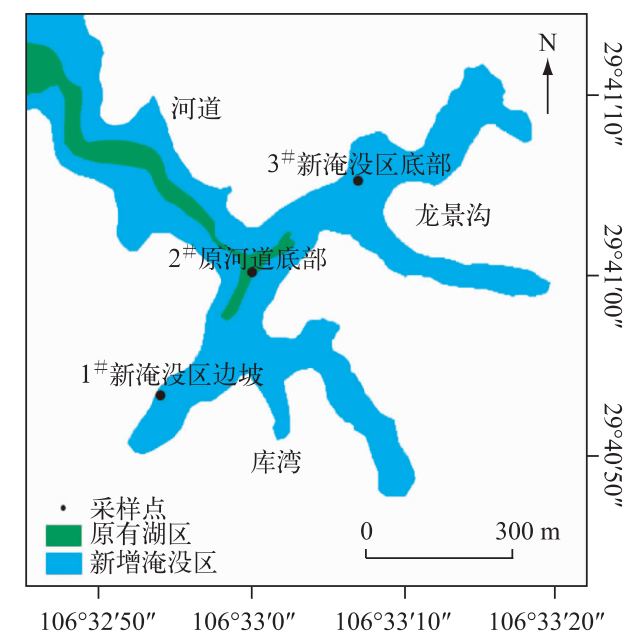

图 1 龙景湖采样点分布

Fig.1 Distribution of sampling sites in Lake Longjing 
别采集龙景湖新淹没区边坡 $\left(1^{\#}\right)$ 、原河道底部 $\left(2^{\#}\right)$ 和新淹没区底部 $\left(3^{\#}\right)$ 的沉积物样品. 采样点使用全球定 位系统(GPS) 定位, 具体位置如图 1 和表 1 所示. 采样时间为 2015 年 9 月 20 日,采样当日湖库及其上游无 降雨. 现场用便携式多参数分析仪 (HACH, HQ40d, USA) 测定沉积物/水界面上方 $30 \mathrm{~cm}$ 上覆水中的 $\mathrm{pH}$ 值、 溶解氧 ( DO) 、电导率 $(\mathrm{Eh})$ 、温度 $(\mathrm{T})$ 等指标 (表 1). 然后用橡胶塞密封柱样, 坚直放置, 运回实验室, $24 \mathrm{~h}$ 内 完成样品预处理和各项指标的测定.

表 1 龙景湖各采样点基本水质参数

Tab.1 Water quality parameters of each sample site in Lake Longjing

\begin{tabular}{lcccccc}
\hline 采样点 & 经纬度 & 水深 $/ \mathrm{m}$ & $\mathrm{pH}$ & $\mathrm{T} /{ }^{\circ} \mathrm{C}$ & $\mathrm{DO} /(\mathrm{mg} / \mathrm{L})$ & 电导率 $/(\mu \mathrm{S} / \mathrm{cm})$ \\
\hline 新淹没区边坡 & $29^{\circ} 40^{\prime} 53^{\prime \prime} \mathrm{N}, 106^{\circ} 32^{\prime} 54^{\prime \prime} \mathrm{E}$ & 10.4 & 6.60 & 24.3 & 2.71 & 439 \\
原河道底部 & $29^{\circ} 41^{\prime} 00^{\prime \prime} \mathrm{N}, 106^{\circ} 33^{\prime} 00^{\prime \prime} \mathrm{E}$ & 16.1 & 7.15 & 21.6 & 1.14 & 547 \\
新淹没区底部 & $29^{\circ} 41^{\prime} 05^{\prime \prime} \mathrm{N}, 106^{\circ} 33^{\prime} 08^{\prime \prime} \mathrm{E}$ & 7.0 & 8.02 & 24.6 & 4.09 & 403 \\
\hline
\end{tabular}

\section{3 样品预处理与测定}

为研究沉积物/水界面附近溶解性有机质的种类及分布, 按照 $1 \mathrm{~cm}$ 间隔分取沉积物/水界面上方 $1 \sim 5$ $\mathrm{cm}$ 的上覆水以及界面以下 $1 \sim 10 \mathrm{~cm}$ 沉积物 (由于 $3^{\#}$ 采样点新淹没区底部沉积物较浅, 采样分离得 $1 \sim 6 \mathrm{~cm}$ 沉积物), 将沉积物置于冷冻离心机 ( 8000 转/ $\mathrm{min}, 10 \mathrm{~min}$ ) 中离心, 上清液即为沉积物孔隙水. 将上覆水和孔 隙水用 $0.45 \mu \mathrm{m}$ 玻璃纤维滤膜( 滤膜预先于马弗炉中 $450^{\circ} \mathrm{C}$ 灼烧 $4 \mathrm{~h}$ ) 过滤, 过滤水样于 $4^{\circ} \mathrm{C}$ 暗处保存, 用于溶 解性有机碳 (DOC) 的测定和光谱分析. DOC 测定采用总有机碳分析仪 (Liqui TOC II , Elementar, Germany), 实验用水均为 Milli-Q 超纯水( Millipore, $18.2 \mathrm{M} \Omega / \mathrm{cm}$ ).

\section{4 光谱扫描与数据分析}

紫外一可见光谱测定采用 U-3010 型紫外一可见分光光度计 (HITACHI, Japan), 于室温下采用 $1 \mathrm{~cm}$ 石英 比色具, 在波长 $200 \sim 700 \mathrm{~nm}$ (间隔为 $1 \mathrm{~nm}$ )下扫描.

特定波长处的吸收系数 $a_{\lambda}$ 根据公式 $(1)$ 计算:

$$
a_{\lambda}=2.303 A_{\lambda} / l
$$

式中, $a_{\lambda}$ 为波长为 $\lambda$ 处的吸收系数 $\left(\mathrm{m}^{-1}\right), A_{\lambda}$ 为波长为 $\lambda$ 处的吸光度, $l$ 为光程差 $(\mathrm{m})$.

三维荧光光谱测定采用 F-7000 型苂光分光光度计 (HITACHI, Japan), 使用 $150 \mathrm{~W}$ 氙弧灯作激发光源, PMT 电压为 $700 \mathrm{~V}$. 菼光激发一发射光谱矩阵的激发波长 $\left(\lambda_{\mathrm{Ex}}\right)$ 和发射波长 $\left(\lambda_{\mathrm{Em}}\right)$ 范围分别为 $200 \sim 450$ 和 $250 \sim 600 \mathrm{~nm}$. $\lambda_{\mathrm{Ex}}$ 与 $\lambda_{\mathrm{Em}}$ 的带通 (Bandpass) 分别为 5 和 $10 \mathrm{~nm}$, 激发和发射的间隔均为 $5 \mathrm{~nm}$, 扫描速度为 1200 $\mathrm{nm} / \mathrm{min}$. 实验空白采用 Milli-Q 超纯水. 使用 SigmaPlot 13.0 软件进行三维苂光光谱图的绘制.

\section{2 结果与讨论}

\subsection{DOM 的紫外一可见吸收光谱特征}

通常, 吸收光谱中波长大于 $230 \mathrm{~nm}$ 的区域为不受无机物 (如氯化物或溴化物等) 干扰的有机物吸收区 域, DOM 的吸光度值随波长的增大而呈指数减小 ${ }^{[17]}$. 由于天然水中 DOM 的发色基团众多, 在光谱中难以区 分, 其紫外一可见光谱表现为谱型较宽、没有特征吸收峰, 因此, 自然水体的吸光度值仅作为溶解性有机碳 ( DOC) 的半定量指标. 常用 $\mathrm{E}_{2} / \mathrm{E}_{3} 、 \mathrm{SUVA}_{254}$ 和 $a_{260}$ 等一系列光谱特征参数和光谱吸收模型来获取 DOM 的各 项信息 ${ }^{[18]}$. 其中, $\mathrm{E}_{2} / \mathrm{E}_{3}\left(a_{250} / a_{365}\right.$, 即水样分别在 250 和 $365 \mathrm{~nm}$ 处的吸收系数之比) 反映了 DOM 的分子量大 小、芳香性、腐殖化程度以及碳的来源. $\mathrm{E}_{2} / \mathrm{E}_{3}$ 值越大, 表明 $\mathrm{DOM}$ 的分子量、芳香性和腐殖化程度越小. $\mathrm{SUVA}_{254}\left(a_{254} / \mathrm{DOC}\right.$, 单位为 $\mathrm{L} /(\mathrm{mg} \cdot \mathrm{m})$ 为水样在 $254 \mathrm{~nm}$ 处的吸收系数与 DOC 值之比) 亦可以反映 DOM 的 芳香化和腐殖化程度 ${ }^{[19]}, \mathrm{SUVA}_{254}$ 值越大, DOM 的芳香化和腐殖化程度越高. $a_{260}$ 为波长为 $260 \mathrm{~nm}$ 处的吸收 系数, 可以表征 DOM 中疏水组分的比例, $a_{260}$ 值越大, 疏水组分比例越高 ${ }^{[20]} .3$ 个采样点沉积物上覆水及孔 隙水中 DOC 及紫外一可见光谱参数 $\left(\mathrm{E}_{2} / \mathrm{E}_{3} 、 \mathrm{SUVA}_{254}\right.$ 和 $\left.a_{260}\right)$ 的值如表 2 所示.

从表 2 可以看出, 同一采样点的上覆水 $\mathrm{E}_{2} / \mathrm{E}_{3}$ 值均大于孔隙水的 $\mathrm{E}_{2} / \mathrm{E}_{3}$ 值, 而 $\mathrm{SUVA}_{254}$ 值均小于孔隙水的 $\mathrm{SUVA}_{254}$ 值, 说明孔隙水中 DOM 的芳香性和腐殖化程度较高. 临近沉积物一水界面层次的上覆水的 $\mathrm{SUVA}_{254}$ 
表 2 龙景湖沉积物上覆水和孔隙水的紫外一可见光谱特征参数

Tab.2 UV-vis spectra characteristic parameters of overlying water and pore water from Lake Longjing sediments

\begin{tabular}{|c|c|c|c|c|c|c|c|c|c|}
\hline \multirow{2}{*}{ 样品属性 } & & \multicolumn{2}{|c|}{$\mathrm{DOC} /(\mathrm{mg} / \mathrm{L})$} & \multicolumn{2}{|c|}{$\mathrm{E}_{2} / \mathrm{E}_{3}$} & \multicolumn{2}{|c|}{$\mathrm{SUVA}_{254} /(\mathrm{L} /(\mathrm{mg} \cdot \mathrm{m}))$} & \multicolumn{2}{|c|}{$a_{260} / \mathrm{m}^{-1}$} \\
\hline & & 范围 & 平均值 & 范围 & 平均值 & 范围 & 平均值 & 范围 & 平均值 \\
\hline \multirow[t]{2}{*}{ 新淹没区边坡 } & 覆水 & $22.6 \sim 25.2$ & $23.6 \pm 1.0$ & $3.13 \sim 6.67$ & $5.32 \pm 1.65$ & $0.968 \sim 2.370$ & $1.400 \pm 0.657$ & $20.7 \sim 53.0$ & $30.8 \pm 14.9$ \\
\hline & 孔隙水 & $39.0 \sim 53.9$ & $44.7 \pm 4.7$ & $3.00 \sim 5.67$ & $4.46 \pm 0.87$ & $1.360 \sim 2.290$ & $1.720 \pm 0.270$ & $57.6 \sim 167.01$ & $106.0 \pm 43.9$ \\
\hline \multirow[t]{2}{*}{ 原河道底部 } & 上覆水 & $23.2 \sim 24.8$ & $24.3 \pm 0.7$ & $4.29 \sim 5.20$ & $4.82 \pm 0.44$ & $0.560 \sim 1.300$ & $1.050 \pm 0.287$ & $13.4 \sim 32.2$ & $25.5 \pm 7.1$ \\
\hline & 孔隙水 & $42.3 \sim 84.3$ & $60.3 \pm 14.7$ & $2.56 \sim 6.00$ & $4.05 \pm 1.03$ & $0.683 \sim 2.270$ & $1.480 \pm 0.495$ & $97.9 \sim 248.01$ & $168.0 \pm 50.0$ \\
\hline \multirow[t]{2}{*}{ 新淹没区底部 } & 上覆水 & $20.7 \sim 22.1$ & $21.6 \pm 0.5$ & $5.75 \sim 9.50$ & $7.45 \pm 1.69$ & $0.892 \sim 0.990$ & $0.971 \pm 0.091$ & $18.4 \sim 24.2$ & $20.7 \pm 2.3$ \\
\hline & 孔隙水 & $30.6 \sim 69.5$ & $46.7 \pm 15.8$ & $4.75 \sim 5.50$ & $5.12 \pm 0.27$ & $1.230 \sim 2.230$ & $1.740 \pm 0.377$ & $46.1 \sim 115.0$ & $80.1 \pm 27.9$ \\
\hline
\end{tabular}

值与表层沉积物的孔隙水接近, 说明界面处上覆水的有机质组成受表层沉积物的影响, 或为采样及运输时 晃动所致. 3 个采样点上覆水的 $a_{260}$ 值显著小于孔隙水的 $(n=41, P<0.05)$, 表明孔隙水中疏水组分含量大于 上覆水. 由于 DOM 中的疏水组分包含了几乎所有的芳香基, 此结果与 $\mathrm{E}_{2} / \mathrm{E}_{3}$ 以及 $\mathrm{SUVA}_{254}$ 的结果一致. 有研 究表明 ${ }^{[18]}$, 富里酸 $(F A)$ 的 $E_{2} / E_{3}$ 值在 4 左右, 而胡敏酸 $(H A)$ 的 $E_{2} / E_{3}$ 值低于富里酸, 本研究可推测新淹没 区边坡和原河道底部沉积物中 DOM 的富里酸/胡敏酸小于新淹没区底部. 腐殖化过程主要由微生物作用, 最终将有机质转变为腐殖质, 从而储存营养物质和能量. 石陶然等 ${ }^{[21]}$ 采用平衡渗析法等技术研究了滇池表 层沉积物中 DOM 的分子量分布特征, DOM 腐殖化程度和芳香性随着分子量的增加而增大. 本研究发现孔 隙水的腐殖化程度和芳香性明显高于上覆水, 表明沉积物孔隙水中大分子量的 DOM 较多, 沉积物中微生物 对有机质的转化起到了重要作用, 而界面上覆水中可能存在内源输人的低分子量 DOM.

\section{$2.2 \mathrm{DOM}$ 的荧光光谱特征}

DOM 的来源可以通过两个苂光指数来表征, 即苂光指数 $\left(F I, f_{450} / f_{500}\right)$ 和生物源指数 $(B I X)$. DOM 的 $F I$ 定义为激发光波长为 $370 \mathrm{~nm}$ 时, 发射波长为 450 与 $500 \mathrm{~nm}$ 时的光谱强度之比, 用于腐殖质 (尤其是富里 酸) 的来源评估 ${ }^{[15]}$. Battin ${ }^{[22]}$ 和 McKnight 等 ${ }^{[23]}$ 利用 $f_{450} / f_{500}$ 对具有复杂发色基团的 DOM 中腐殖质进行溯 源, 陆源 DOM 和生物来源 DOM 这两个端源的 $f_{450} / f_{500}$ 分别为 1.4 和 1.9 , 且受 $\mathrm{pH}$ 影响不大. $F I>1.9$ 时, DOM 主要源于水体自身微生物活动, 自生源特征明显; $F I<1.4$ 时, DOM 以外源输人为主 ${ }^{[24]} . B I X$ 定义为激发波长 为 $310 \mathrm{~nm}$, 发射波长在 380 和 $430 \mathrm{~nm}$ 时苂光强度的比值, 用于评估样本中微生物来源的 DOM 的相对贡献 率 ${ }^{[15]} . B I X$ 值的增加伴随着 $\beta$ 苂光团含量的增加, 而 $\beta$ 苂光团与新近产生的有机质有关 ${ }^{[25]} . B I X<0.6$ 时, 表 示 DOM 中含有较少微生物来源的 DOM; BIX 值的范围为 $0.6 \sim 0.7$ 时, DOM 具有较少的自生组分; $B I X$ 值的 范围为 $0.7 \sim 0.8$ 时, DOM 具有中度新近自生源特征; $B I X$ 值在 $0.8 \sim 1.0$ 之间时, DOM 具有较强自生源特征; $B I X>1.0$ 时, DOM 为生物或者细菌活动产生 ${ }^{[15]}$.

龙景湖沉积物上覆水和孔隙水中 DOM 的 $F I$ 范围为 $1.84 \sim 2.17$, 平均值为 $1.98 \pm 0.07$, 除新淹没区底部沉积 物界面以上 $3 \sim 5 \mathrm{~cm}$ 的上覆水中 DOM 的 $F I$ 值略小于 1.9 外, 其余水样的 $F I$ 值均大于 1.9 (图 2), 这表明龙景 湖上覆水和孔隙水中的 DOM 主要源于水体自身微生物活动, 自生源特征明显. 新淹没区底部(龙景沟) 汇水面 积较大, 汇水区地形呈 $V$ 型峡谷状, 在采样前期降雨中大量营养盐颗粒物和有机碎屑随地表径流经该处的雨、 污水管携人 ${ }^{[16]}$, 导致该区域上覆水的 DOM 可能同时来自陆源和生物源, 该点的沉积物 DOM 来源为生物源.

除少数上覆水样点外, 龙景湖 3 个样点上覆水和孔隙水 DOM 的 $B I X$ 值大小顺序为原河道底部 $>$ 新淹没 区底部>新淹没区边坡. 上覆水中 DOM 的 $B I X$ 值均大于 1 . 对于孔隙水, 原河道底部样点 DOM 的 $B I X$ 值大 于 1 , 新淹没区边坡和新淹没区底部的孔隙水 DOM 的 $B I X$ 值范围为 $0.9 \sim 1.0$. 龙景湖沉积物一水界面上覆水 的 $B I X$ 值大于 1 , 表明 DOM 主要由水体内部生物及细菌活动产生, 同时可能存在新近释放到水体的有机质, 孔隙水 DOM 的 $B I X$ 数值也相对较高 (均 $>0.9$ ), 对应了显著的自生源特征. 该分析结果与 DOM 的苂光指数 所揭示的自生源特征的结果明显一致. 3 个采样点上覆水 DOM 的 BIX 均大于孔隙水 DOM, 而原河道底部孔 隙水 DOM 的 $B I X$ 值大于新淹没区边坡和新淹没区底部, 表明原河道底部沉积物中的生物或细菌更活跃. 原 河道底部沉积物一水界面以下 $0 \sim 3 \mathrm{~cm}$ 的孔隙水的 $B I X$ 值与上覆水差异不大, 这可能是由于原河道采样点水 


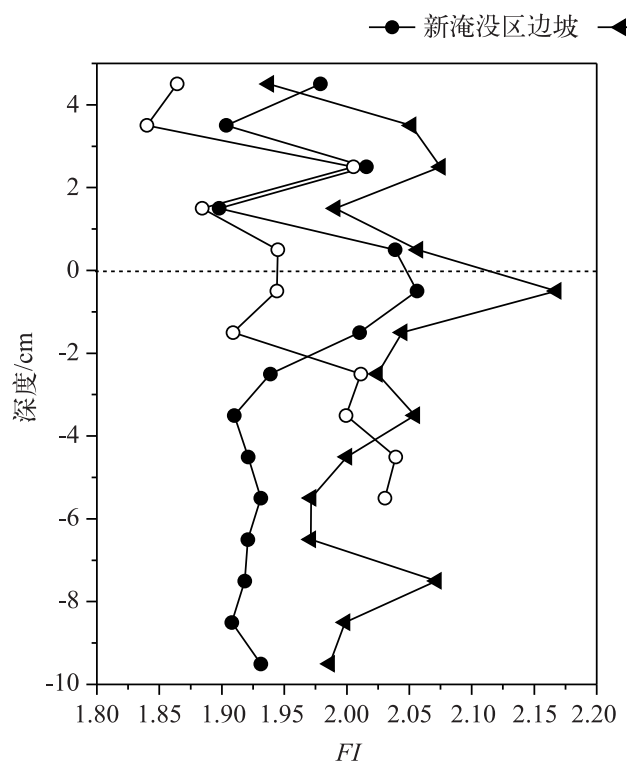

原河道底部 —— 新淹没区底部

图 2 龙景湖沉积物上覆水和孔隙水的苂光指数、生物源指数的垂向分布特征

Fig.2 Vertical profiles of $F I$ and $B I X$ of overlying water and pore water from Lake Longjing sediments

深较深 (达 $16.1 \mathrm{~m}$ ), 水体底部长期厌氧, 沉积物一水界面附近均处于强还原环境, 表层沉积物和上覆水体环 境差异性较小. 综上所述, $F I$ 和 $B I X$ 这 2 种苂光指数在龙景湖沉积物孔隙水中 DOM 的来源上具有良好的指 示性, 揭示了龙景湖沉积物上覆水和孔隙水中的 DOM 主要为生物源, 具有较强的自生源特征.

\section{表 3 龙景湖沉积物上覆水及孔隙水中 DOM 的主要苂光峰 ${ }^{[23]}$}

Tab.3 Main fluorescence peaks of DOM in overlying water and pore water from Lake Longjing sediments

\begin{tabular}{cccc}
\hline 谱峰名 & 类型 & $\lambda_{\mathrm{Ex}}(\mathrm{nm}) / \lambda_{\mathrm{Em}}(\mathrm{nm})$ \\
\hline $\mathrm{C}$ & & 类富里酸若光峰 & $320 \sim 380 / 420 \sim 500$ \\
$\mathrm{~A}$ & & 类富里酸菼光峰 & $230 \sim 260 / 400 \sim 480$ \\
$\mathrm{~T}$ & $\mathrm{~T}_{1}$ & 类色氨酸菼光峰 & $270 \sim 280 / 334 \sim 360$ \\
& $\mathrm{~T}_{2}$ & 类色氨酸菼光峰 & $220 \sim 235 / 334 \sim 360$ \\
$\mathrm{~B}$ & $\mathrm{~B}_{1}$ & 类酪氨酸若光峰 & $270 \sim 280 / 304 \sim 310$ \\
& $\mathrm{~B}_{2}$ & 类酪氨酸菼光峰 & $220 \sim 235 / 304 \sim 310$ \\
\hline
\end{tabular}

\section{$2.3 \mathrm{DOM}$ 的三维荧光光谱}

由于苂光光谱性质分析中苂光指数等指标 在苂光性质的定量分析上缺乏解析芳香族 DOM 异质性的能力,因此需要利用苂光激发一发射光 谱矩阵来得到更多的荧光光谱信息, 以进一步分 析龙景湖沉积物上覆水及孔隙水中 DOM 的组成 及来源. 通过苂光激发一发射光谱矩阵绘制的三 维苂光光谱图,可以直观地发现不同来源的 DOM 因其含有不同的苂光基团,在图中显示为不同位 置的荧光峰. 根据 Chen 等 ${ }^{[26]}$ 的研究结果对三维 苂光光谱图进行区域划分, 龙景湖沉积物上覆水 和孔隙水样共得到 6 种主要的苂光峰 (表 3 ). 苂

光峰 A、C 属于类腐殖酸苂光, 代表较难降解的 DOM, 被认为与腐殖质结构中的羰基和羧基有关, 主要来自 于陆源输人. 菼光峰 $\mathrm{C}$ 属于类腐殖酸, 通常被临近的苂光峰 (如 $\mathrm{T}_{1}$ 峰) 覆盖一部分, 对其苂光中心的研究报 道较少. 有研究将 $\mathrm{C}$ 峰归因于类腐殖有机物, 由木质素和其他降解的植物的不同分子组成, 是市政固体废物 中 $\mathrm{C}$ 峰的潜在贡献者. $\mathrm{T}$ 峰和 $\mathrm{B}$ 峰合称为类蛋白苂光峰, 与微生物活动相关, 可以通过外源进人湖泊或微生 物活动产生 ${ }^{[27]} . \mathrm{B}$ 峰 (包括两个不同峰位的 $\mathrm{B}_{1}$ 峰和 $\mathrm{B}_{2}$ 峰) 代表的类酪氨酸物质, 可以是自由分子或与氨基 酸、蛋白质结合, 而与 $\mathrm{T}$ 峰 (包括两个不同峰位的 $\mathrm{T}_{1}$ 和 $\mathrm{T}_{2}$ 峰) 相关的类色氨酸化合物, 可以是自由分子或与 蛋白质、杀虫剂、腐殖质结构相结合.

3 个采样点沉积物上覆水及孔隙水中 DOM 的三维荧光光谱如图 3 5 所示. 3 个采样点所有水样均不同 程度地出现 $\mathrm{A}$ 峰、 $\mathrm{B}$ 峰和 $\mathrm{T}$ 峰, 且在较深层次孔隙水中不同程度地出现 $\mathrm{C}$ 峰.

新淹没区边坡沉积物上覆水中显示 4 个类蛋白峰 $\left(B_{1} 、 B_{2} 、 T_{1}\right.$ 和 $\left.T_{2}\right)$ 和 $A$ 峰 (图 3), 其中 $B_{1}$ 峰和 $T_{2}$ 峰很 


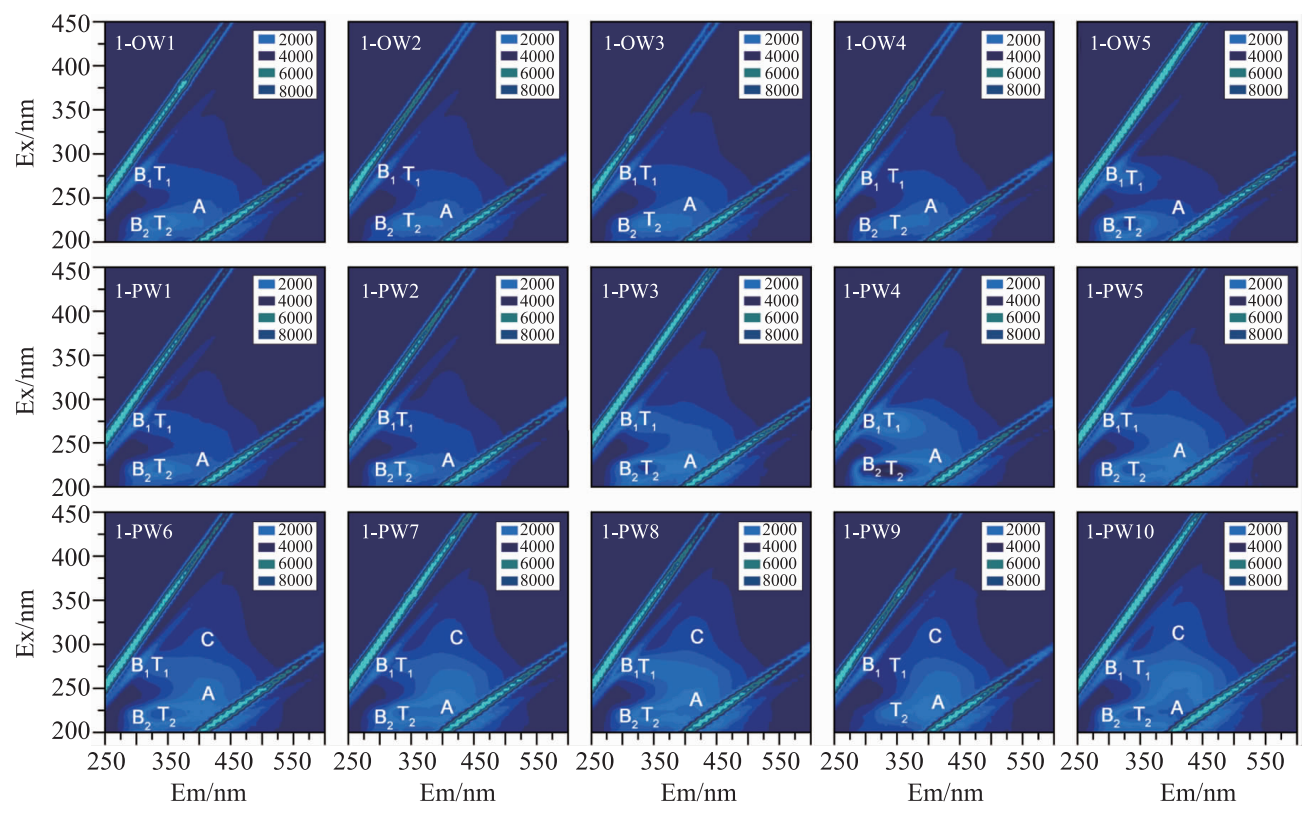

图 3 新淹没区边坡沉积物上覆水及孔隙水中 DOM 的三维苂光光谱

(其中, 1-OW 1 1-OW5 为上覆水, 1-PW 1 1-PW 10 为孔隙水)

Fig.3 Three-dimensional fluorescence spectra of DOM in overlying water and pore water from newly submerged sediment along the lakeside

明显, $\mathrm{B}_{2}$ 峰和 $\mathrm{T}_{1}$ 峰向沉积物一水界面方向有增强趋势, 上覆水中出现类腐殖酸峰 ( $\mathrm{A}$ 峰), 说明可能存在陆源 有机质输人. 由于龙景湖在建湖时已经切断了除面源外的其他外源性污染源, 故认为可能是地表径流、降雨 等导致的陆源输人. 孔隙水中 4 个类蛋白峰、 $\mathrm{A}$ 峰和 $\mathrm{C}$ 峰都存在, 表层孔隙水 $(0 \sim 5 \mathrm{~cm})$ 的 $\mathrm{B}_{2}$ 峰和 $\mathrm{T}_{2}$ 峰较深 层孔隙水和界面上覆水更为明显, 仅在深层孔隙水中存在 $\mathrm{C}$ 峰 $(6 \sim 10 \mathrm{~cm})$. 在深层孔隙水中, $\mathrm{A}$ 峰和 $\mathrm{C}$ 峰随 深度的增加而变强, 而 $\mathrm{B}$ 峰和 $\mathrm{T}$ 峰逐渐减弱. 根据荧光峰的分布及变化规律可知, 新淹没区边坡沉积物上覆 水和表层孔隙水中 DOM 以色氨酸和酪氨酸等芳香族类蛋白物质为主, 且表层沉积物孔隙水中的类蛋白物 质含量高于上覆水, 深层孔隙水中含有大量的类腐殖质. 这是由于表层沉积物中有机质含量较高, 微生物通 过有氧或厌氧呼吸降解有机物并产生大量的可溶性副产物, 成为上覆水 DOM 的来源之一. 结合成湖背景进 行分析, 新淹没边坡在成湖前属山林或农田土地, 建湖后形成新淹没区, 建湖初期并未对湖泊及其周围区域 进行清库处理, 边坡残留了原始植被和土壤, 导致深层沉积物中腐殖质含量较高. 李昆等 ${ }^{[28]}$ 在研究城市雨 水管网沉积物中不同分子量 DOM 的空间分布时发现, 腐殖类物质主要集中在大分子量 (大于 $10 \mathrm{kDa}$ ) DOM 区域且随分子量增大 DOM 腐殖化程度升高, 小分子量 (小于 $3 \mathrm{kDa}$ ) DOM 主要是类蛋白物质, 此结论与紫 外一可见光谱特征指标 $E_{2} / E_{3}$ 的认定一致. 综上, 新淹没区边坡沉积物上覆水和表层孔隙水的 DOM 以小分 子量类蛋白物质为主, 深层孔隙水中含有大量的大分子类腐殖质, 且随着深度的增加, 腐殖化程度升高. 此 结果与前文紫外一可见光谱分析结论中 $\mathrm{E}_{2} / \mathrm{E}_{3} 、 \mathrm{SUVA}_{254} 、 a_{260}$ 所揭示的结果一致.

如图 4 所示, 和新淹没区边坡相似, 原河道底部沉积物上覆水显示 4 个类蛋白峰和 $\mathrm{A}$ 峰, $\mathrm{B}_{1}$ 和 $\mathrm{T}_{2}$ 峰较 强, $\mathrm{B}_{2} 、 \mathrm{~T}_{1}$ 和 $\mathrm{A}$ 峰较弱. 孔隙水中出现 4 个类蛋白峰、 $\mathrm{A}$ 峰和 $\mathrm{C}$ 峰, 表层孔隙水 $(1 \sim 5 \mathrm{~cm})$ 中苂光峰很集中, $\mathrm{B}$ 峰和 $\mathrm{T}$ 峰较为突出, 这表明类色氨酸和类酪氨酸物质是表层孔隙水 DOM 中的主要组分. 随着深度的进一步 增加, 孔隙水中 $\mathrm{T}_{1}$ 峰减弱, $\mathrm{A}$ 峰增强并在 6 10 $\mathrm{cm}$ 孔隙水中出现 $\mathrm{C}$ 峰, $\mathrm{C}$ 峰的强度也有增强趋势. 与新淹没 边坡相比, 原河道深层孔隙水 $(6 \sim 10 \mathrm{~cm})$ 中 $\mathrm{B}_{2}$ 和 $\mathrm{T}_{2}$ 峰较强. 这可能是由于龙景湖蓄水前未进行原河道的清 淤处理, 该区域沉积物较厚且水深较深 $(16.1 \mathrm{~m})$, 深层沉积物的厌氧还原环境和充足的营养供给等条件, 促 使微生物活性较强, 与微生物活性相关的 B 和 $\mathrm{T}$ 峰较强. 上述苂光光谱 $B I X$ 指标也表明, 原河道沉积物中的 

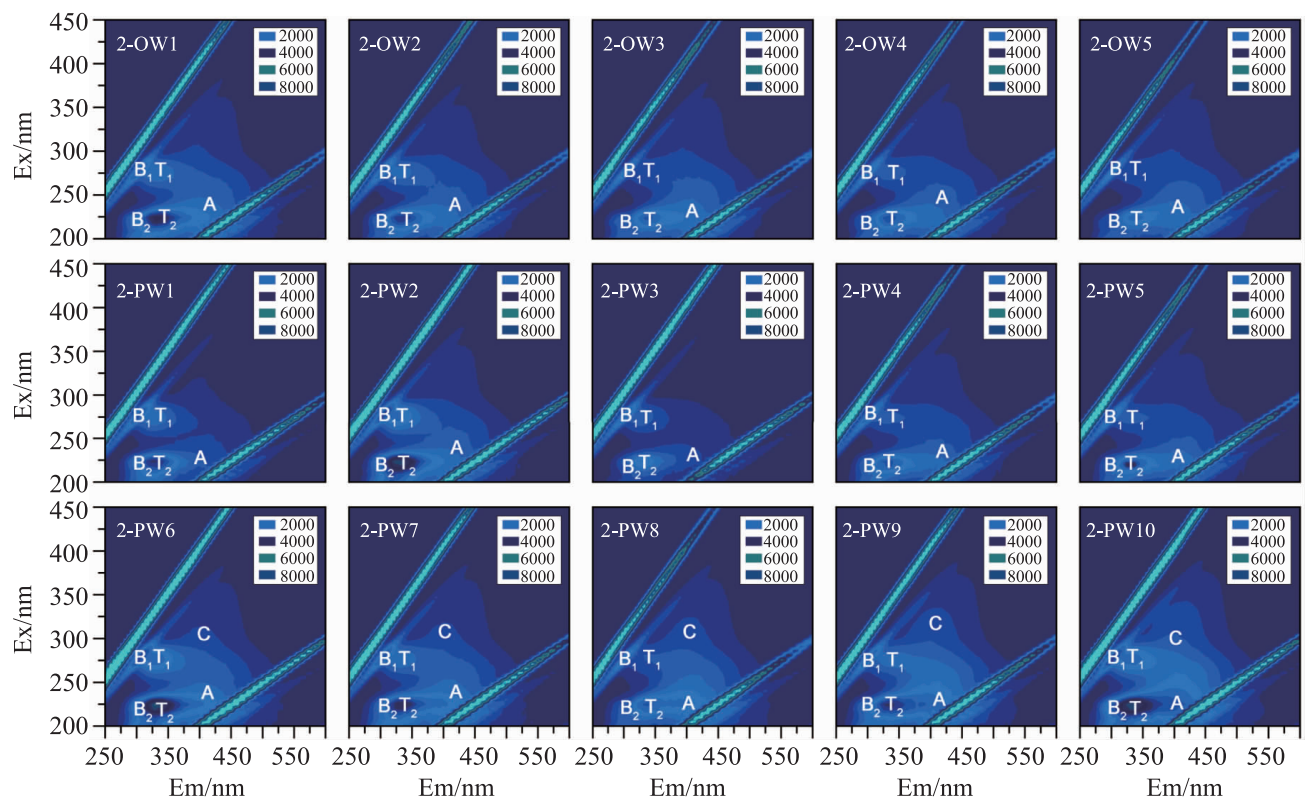

$\begin{array}{lllllllllll}350 & 450 & 550 & 250 & 350 & 450 & 550 & 250 & 350 & 450 & 550\end{array}$

$\mathrm{Em} / \mathrm{nm}$

$\mathrm{Em} / \mathrm{nm}$

$\mathrm{Em} / \mathrm{nm}$

图 4 原河道底部沉积物上覆水及孔隙水中 DOM 的三维苂光光谱

(其中, 2-OW1 2-OW5 为上覆水, 2-PW1 2-PW10 为孔隙水)

Fig.4 Three-dimensional fluorescence spectra of DOM in overlying water and pore water from original riverbed sediment

生物或细菌较新淹没区边坡和新淹没区底部更活跃. 因此, 原河道底部沉积物上覆水和表层孔隙水的 DOM 以类蛋白物质为主,深层孔隙水中同时含有类蛋白物质和类腐殖质.

新淹没区底部沉积物上覆水中主要显示 $\mathrm{B}_{1} 、 \mathrm{~T}_{2}$ 峰, 界面上 $3 \sim 5 \mathrm{~cm}$ 上覆水中不存在 $\mathrm{B}_{2}$ 峰, $\mathrm{B}_{2} 、 \mathrm{~T}_{1} 、 \mathrm{~T}_{2}$ 和 $\mathrm{A}$ 峰向界面方向逐渐增强. 新淹没区底部沉积物孔隙水的三维荧光光谱荧光结构与上述样品的结构稍有不 同, 在 3 4 cm 孔隙水中就开始出现 $\mathrm{C}$ 峰, 且随着深度的逐渐增强 (图 5). 这表明相比于新淹没区边坡和原 河道底部, 新淹没区边坡沉积物的孔隙水中类腐殖质含量最高, 与前述紫外一可见光谱特征中各指标平均值 表征结果相同. 再者, 在沉积物/水界面附近 (界面上 $2 \mathrm{~cm}$ 上覆水和界面下 $2 \mathrm{~cm}$ 孔隙水) B 峰和 $\mathrm{T}$ 峰较弱, 表 明新淹没区底部沉积物一水界面附近微生物活性不强. 这可能是因为蓄水前新淹没底部主要为裸露土壤和 碎石表层,加之该点水深相对较浅 $(7 \mathrm{~m})$, 致使表层沉积物微生物活性较弱.

\section{3 结论}

1) 龙景湖沉积物孔隙水中 DOM 的芳香性和腐殖化程度高于上覆水, 疏水组分在孔隙水中的相对含量 高于上覆水, 界面上覆水体中可能存在内源输人的低分子量 DOM ; 新淹没边坡和原河道底部沉积物中富里 酸/胡敏酸比值低于新淹没底部.

2) 龙景湖沉积物上覆水和孔隙水中的 DOM 主要源于水体自身生物或者细菌活动, 具有较强的自生源 特征且沉积物存在向上覆水释放有机质的潜力.

3) 龙景湖新淹没区边坡沉积物上覆水和表层孔隙水中的 DOM 以小分子量类蛋白物质为主, 深层孔隙 水中含有大量的大分子类腐殖质, 且随着深度的增加, 腐殖化程度升高. 原河道底部沉积物上覆水和表层孔 隙水的 DOM 以类蛋白物质为主, 深层孔隙水中同时含有类蛋白物质和类腐殖质. 新淹没区底部沉积物上覆 水 DOM 主要为类蛋白物质, 接近沉积物一水界面的上覆水出现类腐殖质物质且浓度向界面方向逐渐升高, 孔隙水 DOM 中类腐殖质含量较另外两个采样点更高. 以上苂光光谱特征与龙景湖的建湖背景有一定联系, 此部分结论与紫外一可见光谱特征结论具有一致性. 

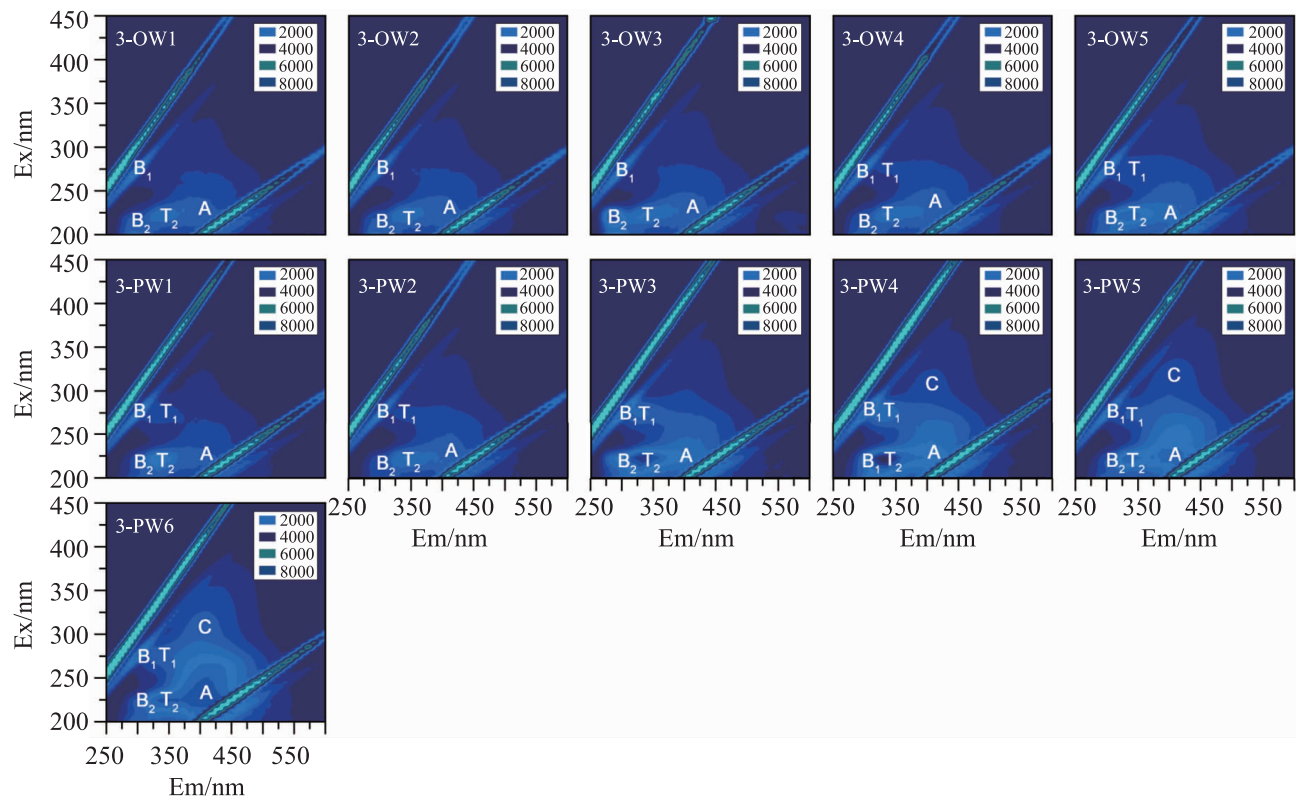

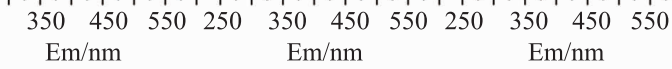

图 5 新淹没区底部沉积物上覆水及孔隙水中 DOM 的三维苂光光谱 (其中, 3-OW1 3-OW5 为上覆水, 3-PW1 3-PW6 为孔隙水)

Fig.5 Three-dimensional fluorescence spectra of DOM in overlying water and pore water from newly submerged bottom sediment

\section{4 参考文献}

[ 1 ] Fu PQ, Wu FC, Liu CQ et al. Three-dimensional excitation emission matrix fluorescence spectroscopy of dissolved organic matter from Chinese highland lakes. Oceanologia et Limnologia Sinica, 2007, 38(6) : 512-520. [傅平青, 吴丰昌, 刘丛 强等. 高原湖泊溶解有机质的三维苂光光谱特性初步研究. 海洋与湖沼, 2007, 38(6) : 512-520.]

[ 2 ] Birdwell JE, Engel AS. Characterization of dissolved organic matter in cave and spring waters using UV-Vis absorbance and fluorescence spectroscopy. Organic Geochemistry, 2010, 41(3): 270-280.

[ 3 ] Yao X, Zhang Y, Zhu G et al. Resolving the variability of CDOM fluorescence to differentiate the sources and fate of DOM in Lake Taihu and its tributaries. Chemosphere, 2011, 82(2) : 145-155.

[ 4 ] Wang L, Wu FC, Zhang R et al. Characterization of dissolved organic matter fractions from Lake Hongfeng, Southwestern China Plateau. Journal of Environmental Sciences, 2009, 21(5) : 581.

[ 5 ] Leenheer JA, Nanny MA, Mcintyre C. Terpenoids as major precursors of dissolved organic matter in landfill leachates, surface water, and groundwater. Environmental Science and Technology, 2003, 37(11) : 2323-2331.

[ 6 ] Zhang Z, Yang DX, Wang B et al. Study on water environment characteristics of an incipient artificial lake. Chinese Journal of Environment Engineering, 2010, (6): 1321-1326. [张智, 杨冬雪, 王斌等. 某人工湖成库初期水环境特征研 究. 环境工程学报, 2010, (6) : 1321-1326.]

[ 7 ] Ioriya $\mathrm{T}$, Inoue S, Haga M et al. Change of chemical and biological water environment at a newly constructed reservoir. Water Science and Technology, 1998, 37(2) : 187-194.

[ 8 ] Wei H, Jung H, Lee JH et al. Differences in spectroscopic characteristics between dissolved and particulate organic matters in sediments: Insight into distribution behavior of sediment organic matter. Science of the Total Environment, $2016, \mathbf{5 4 7}$ : 1-8.

[ 9 ] Shank GC, Zepp RG, Whitehead RF et al. Variations in the spectral properties of freshwater and estuarine CDOM caused by partitioning onto river and estuarine sediments. Estuarine Coastal and Shelf Science, 2005, 65(1/2):289-301.

[10] Ji FY, Li S, Zhou GM et al. Study of the fluorescence characteristics of DOM from the Yangtze River and Jialing River a- 
round Chongqing's urban areas. Spectroscopy and Spectral Analysis, 2010, 30(1) : 233-238. [吉芳英, 黎司, 周光明等. 重庆主城区两江溶解有机质的苂光光谱特征. 光谱学与光谱分析, 2010, 30(1) : 233-238.]

[11] Xu H, Yu G, Jiang H. Investigation on extracellular polymeric substances from mucilaginous cyanobacterial blooms in eutrophic freshwater lakes. Chemosphere, 2013, 93(1): 75-81.

[12] Feng JY, Jiao LX, Zhang S et al. Spectral characteristics of dissolved organic matter in the sediments of Wuliangsuhai Lake. China Environmental Science, 2013, 33(6) : 1068-1074. [冯伟芗, 焦立新, 张生等. 乌梁素海沉积物溶解性有 机质荧光光谱特性. 中国环境科学, 2013, 33(6): 1068-1074.]

[13] Wang LY, Zhang RY, Wu FC. Spectrum characteristics and spatial distribution of dissolved organic matter in sediment porewater from northern Dianchi Lake. Chinese Journal of Ecology, 2014, 33(12) : 3416-3422. [王立英, 张润宇, 吴丰 昌. 滇池北部沉积物孔隙水中溶解性有机质的光谱特性与空间分异. 生态学杂志, 2014, 33(12) : 3416-3422.]

[14] Xiao LG, Chen WS, Chen GF et al. Fluorescence excitation-emission matrix spectroscopy of chromophoric organic matter in the South China Sea. Acta Scientiae Circumstantiae, 2014, 34(1) : 160-167. [肖隆庚, 陈文松, 陈国丰等. 中国南海 CDOM 三维苂光光谱特征研究. 环境科学学报, 2014, 34(1) : 160-167.]

[15] Huguet A, Vacher L, Relexans S et al. Properties of fluorescent dissolved organic matter in the Gironde Estuary. Organic Geochemistry, 2009, 40(6) : 706-719.

[16] Ji FY, Yan HB, He Q et al. Distribution of nitrogen speciation at the sediment-water interface in Longjinggou catchment area of Longjinghu Lake. China Environmental Science, 2015, 35(10) : 3101-3107. [吉芳英, 颜海波, 何强等. 龙景湖 龙景沟汇水区沉积物-水界面氮形态空间分布特征. 中国环境科学, 2015, 35(10): 3101-3107.]

[17] Twardowski MS, Boss E, Sullivan JM et al. Modeling the spectral shape of absorption by chromophoric dissolved organic matter. Marine Chemistry, 2004, 89(1/2/3/4) : 69-88.

[18] Barreto SRG, Nozaki J, Barreto WJ. Origin of dissolved organic carbon studied by UV-vis spectroscopy. Acta Hydrochimica Et Hydrobiologica, 2004, 31(6): 513-518.

[19] Helms JR, Stubbins A, Ritchie JD et al. Absorption spectral slopes and slope ratios as indicators of molecular weight, source, and photobleaching of chromophoric dissolved organic matter. Limnology and Oceanography, 2008, 53 ( 3 ) : 955-969.

[20] Dilling J, Kaiser K. Estimation of the hydrophobic fraction of dissolved organic matter in water samples using UV photometry. Water Research, 2002, 36(20) : 5037-5044.

[21] Shi TR, Zhang Y, Yu T et al. Distribution of different molecular weight fractions of dissolved organic matters and their complexation with $\mathrm{Cu}$ and $\mathrm{Pb}$ in the sediment from Dianchi Lake, China. Research of Environmental Sciences, 2013,26 (2) : 137-144. [石陶然, 张远, 于涛等. 滇池沉积物不同分子量溶解性有机质分布及其与 $\mathrm{Cu}$ 和 $\mathrm{Pb}$ 的相互作用. 环境科学研究, 2013, 26(2): 137-144.]

[22] Battin TJ. Dissolved organic matter and its optical properties in a blackwater tributary of the upper Orinoco river, Venezuela. Organic Geochemistry, 1998, 28(9/10): 561-569.

[23] Mcknight DM, Boyer EW, Westerhoff PK et al. Spectrophotometric characterization of dissolved organic matter for indication of precursor organic material and aromaticity. Limnology and Oceanography, 2001, 46(1) : 38-48.

[24] Lu S, Jiang T, Zhang JZ et al. Three-dimensional fluorescence characteristic differences of dissolved organic matter (DOM) from two typical reservoirs. China Environmental Science, 2015, 35(2): 516-523. [卢松, 江韬, 张进忠等. 两 个水库型湖泊中溶解性有机质三维菼光特征差异. 中国环境科学, 2015, 35(2): 516-523.]

[25] Parlanti E, Wörz K, Geoffroy L et al. Dissolved organic matter fluorescence spectroscopy as a tool to estimate biological activity in a coastal zone submitted to anthropogenic inputs. Organic Geochemistry, 2000, 31(12) : 1765-1781.

[26] Chen W, Westerhoff P, Leenheer JA et al. Fluorescence excitation-emission matrix regional integration to quantify spectra for dissolved organic matter. Environmental Science and Technology, 2003, 37(24):5701.

[27] Hudson N, Baker A, Ward D et al. Can fluorescence spectrometry be used as a surrogate for the Biochemical Oxygen Demand (BOD) test in water quality assessment? An example from South West England. Science of the Total Environment, $2008,391(1): 149-158$.

[28] Li K, Li HY. Spatial distribution and spectral characteristic of dissolved organic matter with different molecular weight in urban rainwater sewer sediment. Environmental Monitoring in China, 2016, 32(2): 109-115. [李昆, 李海燕. 城市雨水 管网沉积物不同分子量溶解性有机质空间分布及光谱特征. 中国环境监测, 2016, 32(2) : 109-115.] 